\title{
Aicardi Syndrome with Peripapillary Staphyloma: A Case Report and Review of Literature
}

\author{
Jessica Belle A. Sy, MD¹ and Roland Joseph D. Tan, MD, MS ${ }^{1,2}$ \\ ${ }^{1}$ Baguio General Hospital and Medical Center, Baguio City, Philippines \\ ${ }^{2}$ Department of Ophthalmology and Visual Sciences, College of Medicine and Philippine General Hospital, University of the Philippines Manila
}

\begin{abstract}
Aicardi Syndrome (AS) is a rare X-linked congenital disorder traditionally characterized by a triad of dysgenesis of corpus callosum, seizures, and chorioretinal abnormalities. Patients often have severe psychomotor delay and shortened life expectancy. However, Aicardi syndrome is a clinically heterogeneous disorder. We present a case of a 14-year-old with the traditional triad of history of infantile spasm, complete agenesis of the corpus callosum, and chorioretinal abnormality but with peripapillary staphyloma and with no psychomotor delays. Based on the review of literature, this is the first reported case of AS in the Philippines, the first reported case of AS with peripapillary staphyloma, and is one of the 3 reported cases of AS with normal psychomotor development. There remains no factor that can prognosticate cognitive function in AS at present including genetic testing.
\end{abstract}

Keywords: Aicardi syndrome, Callosal agenesis, infantile spasms, chorioretinal lacunae, peripapillary staphyloma

\section{INTRODUCTION}

Aicardi syndrome (AS) is a rare $\mathrm{X}$-linked disorder predominantly affecting females with estimated incidences of 1 in 99,000 live births in Europe and 1 in 105,000 in the United States. ${ }^{1,2}$ It is traditionally diagnosed based on the presence of the triad of partial or total agenesis of the corpus callosum, infantile spasms, and chorioretinal abnormalities. ${ }^{1}$ Other reported findings in cranial imaging are macroscopic migration, ventriculomegaly, heterotopias, asymmetry, pachygyria, or lissencephaly of the cerebrum, pachygyria, microcephaly, polymicrogyria, porencephaly, cysts, papilloma, and cerebellar anomalies..$^{3-8}$ Aside from infantile spasms, an individual with AS can also suffer seizure that is atonic, tonic, clonic, tonic-clonic, myoclonic, bilateral myoclonic, complex partial or autonomic. The seizure can also be gelastic, absent, febrile, emotional, catamenial, or hypoxic. ${ }^{6}$ Other reported ophthalmological findings include pupillary membrane, cataract, microphthalmia, macular scar, retinal detachment, morning glory disc anomaly, optic nerve hypoplasia, dysplasia, pigmentation or coloboma, and retrobulbar cyst. ${ }^{3,6,7,9,10}$

Other associated physical findings in AS involve the skeletal system (kyphosis, scoliosis, rib abnormalities), gastrointestinal system (gastroesophageal reflux, constipation, diarrhea, difficulty in feeding and abdominal pain), pulmonary system (apnea and seizure-related aspiration and pneumonia),

Corresponding author: Roland Joseph D. Tan, MD, MS Baguio General Hospital and Medical Center Baguio City, Philippines Email:rdtan@up.edu.ph and genitourinary system (antiseizure medication-related kidney stones and catheter-related infections). ${ }^{6}$ Craniofacial (cleft lip and palate, Pierre Robin sequence, plagiocephaly), skin (pigmentated lesions and vascular malformations), and 
endocrine abnormalities (precocious or delayed puberty) have also been documented. ${ }^{6}$ The pathophysiology of AS remains unknown. Typically, patients with AS have poor outcomes due to severe global developmental delay with no learned meaningful language and occasional ambulatory skills and are associated with shortened life expectancy with a reported mean age of 8.3 years. ${ }^{6}$

However, severity and presentation of AS vary due to its heterogeneity, with mild presentation occurring but rarely. ${ }^{1}$ Thus, we present a case of a 14-year-old female with the traditional triad of AS but with new ophthalmological findings and with normal cognitive functions.

\section{CASE PRESENTATION}

This is a case of a 14-year-old female who consulted for blurring of vision of the right eye verbalized at the age of 11 years. There was no other ophthalmologic complaint. Her past medical history is unremarkable. She is the only child and there is no similar eye problem in the family. She was born preterm at 7 months gestational age via Caesarian section to a then 32-year-old mother due to maternal preeclampsia. Infantile spasms characterized as jerking of both upper and lower extremities were noted at 1 month of life with no consult done due to financial constraints. No recurrence of the spasms was noted while growing up.

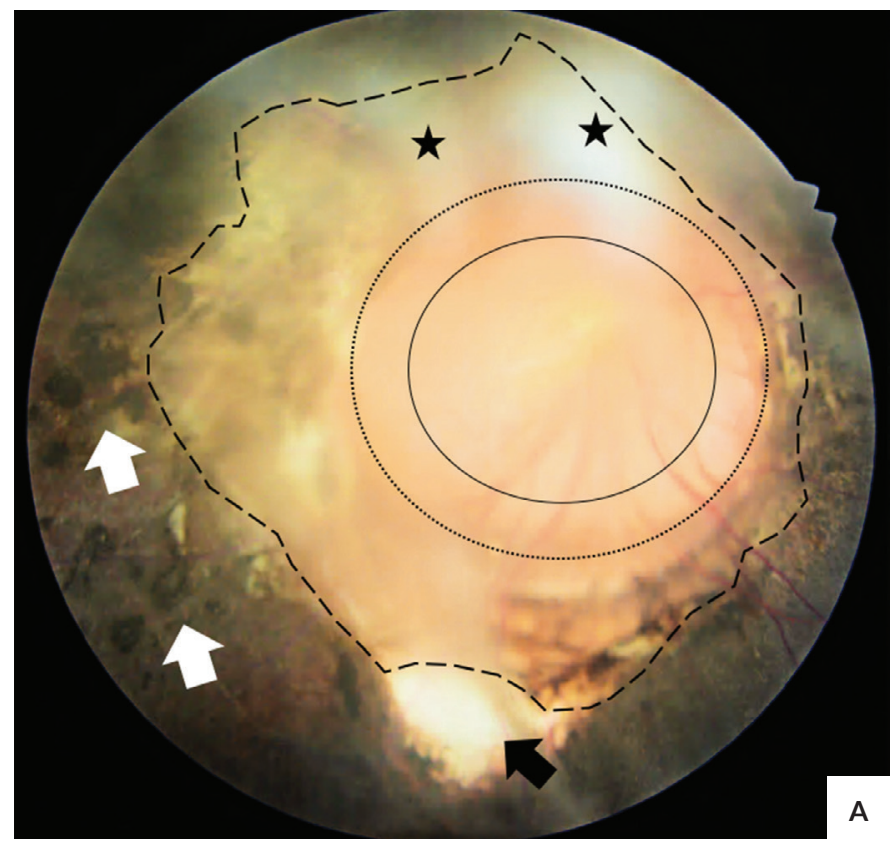

At the consult, physical and neurological examinations were unremarkable. Ophthalmologic examination revealed visual acuities of light perception in the right eye and 6/6 in the left eye, full extraocular muscle movements, within normal intraocular pressures, and normal anterior segment findings. A relative afferent pupillary defect of the right eye was noted. Retinoscopy could not be performed in the right eye to determine refraction due to the absence of light reflex. Refraction on the left eye is -2.00 . Fundoscopy of the right eye revealed an excavation surrounding a large optic nerve with associated pigmentary changes including a hypopigmented area inferotemporal. (Figure 1). Findings in the left eye are all within normal limits.

The initial ophthalmological impression was morning glory disc anomaly (MGDA) since MGDA presents with a funnel-shaped excavation surrounding an optic nerve that resembles the similarly named flower. However, upon closer examination of our patient's right eye, there is no characteristic white glial tuft of MGDA in the center of a relatively normal optic nerve and vessels coming out of it have a central branching pattern as opposed to being radially oriented. Similarly, an area of the initially considered excavation was already a segment of a huge optic nerve ( $>14$ millimeter ${ }^{2}$ ) with an enlarged cup. The small hypopigmented area inferotemporal to the optic nerve (black arrow in Figure 1 ) is chorioretinal lacunae which is associated with AS.

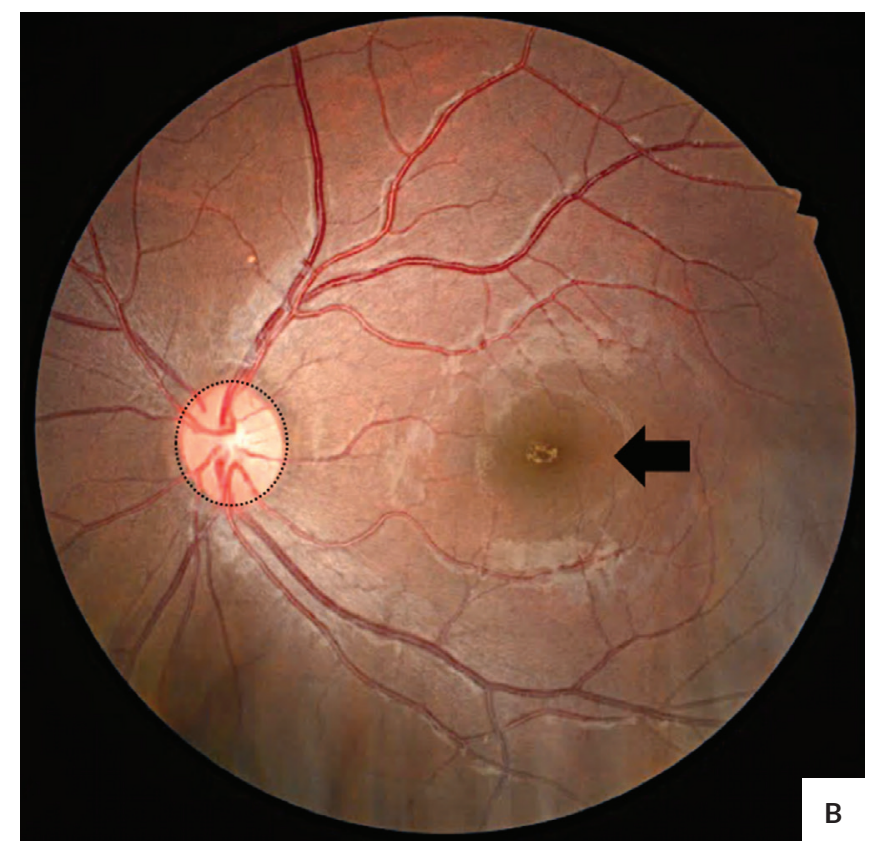

Figure 1. (A) Color fundus photo of the right eye showing thru mild superior vitreous haze (black stars) a posteriorly displaced normal but enlarged optic disc with distinct borders (dotted line oval) and enlarged cup (solid line oval) surrounded by an irregularly-shaped staphyloma (outer dashed line) and pigmentary changes (white arrows) and vessels emanating nonradially from the nerve. A hypopigmented area (black arrow) is seen inferotemporal to the disc suggestive of a chorioretinal lacunae. Macula is not appreciated. (B) Color fundus photo of the left eye showing thru clear media a regular-sized normal orange optic nerve with distinct borders (dotted line oval), vessels following a normal course, and a good foveal reflex (black arrow). 
Coloboma of the optic disc and retina were not considered since there was no missing optic disc segment and although there was a small hypopigmented area in the retina corresponding to the lacunae, it is not located inferonasal to the nerve, the area where colobomas are found.

Due to the known association of AS to neurological abnormalities and the uninvestigated history of infantile spasms, the patient was referred to the Pediatric Neuroscience Service who ordered a cranial Magnetic Resonance Imaging which revealed total agenesis of the corpus callosum with colpocephaly (Figure 2) and psychological testing. A Stanford-Binet test revealed average intelligence equivalent to an intelligence quotient of 90-109. The patient was then referred to the Developmental and Behavioral Pediatrics Service who assessed the patient with essentially normal development.

The imaging also revealed a focal posterior defect with vitreous outpouching in the optic nerve of the right globe, which is probably the reason it is smaller than the left globe (Figure 3). The outward slanting of the excavation in the optic nerve as seen in the imaging suggests a peripapillary staphyloma more than a funnel-shaped MGDA. Optical computed tomography of the right optic nerve was attempted but not done due to its posterior displacement.

With the addition of the callosal agenesis, a diagnosis of AS was made. She was referred to Pediatrics for further evaluation. The patient has appropriate weight and height for her age and with normal physical examination results. She was found to have a normal cognitive function with at par intelligence quotient for her age and no motor deficiencies. Developmental milestones are not delayed. Electroenchepalogram (EEG) was normal.

Since AS is an X-linked disorder, the patient's mother was also assessed. However, she has no ophthalmologic abnormalities, has a normal cognitive function, and no history of childhood epilepsy. As such, a cranial MRI was no longer requested. There is no similar illness among women in their immediate relatives.

\section{DISCUSSION}

The presence of the traditional triad of small chorioretinal lacunae, corpus callosal agenesis, and history of infantile spasms in our patient made us diagnose her with AS. However, our patient also presented with megalopapilla and peripapillary staphyloma, ophthalmological findings which were not previously reported in AS. Megalopapilla is a clinical term used to describe a congenital optic disc anomaly where the disc diameter is enlarged to more than 2.5 square millimeters but with a normal appearance and normal vessel orientation. ${ }^{11}$ Its pathophysiology is unknown. When it is associated with another congenital optic disc anomaly such as peripapillary staphyloma, the latter is used as the diagnosis. ${ }^{12}$ The optic cup is also enlarged in some reported cases including our patient, which can be mistaken

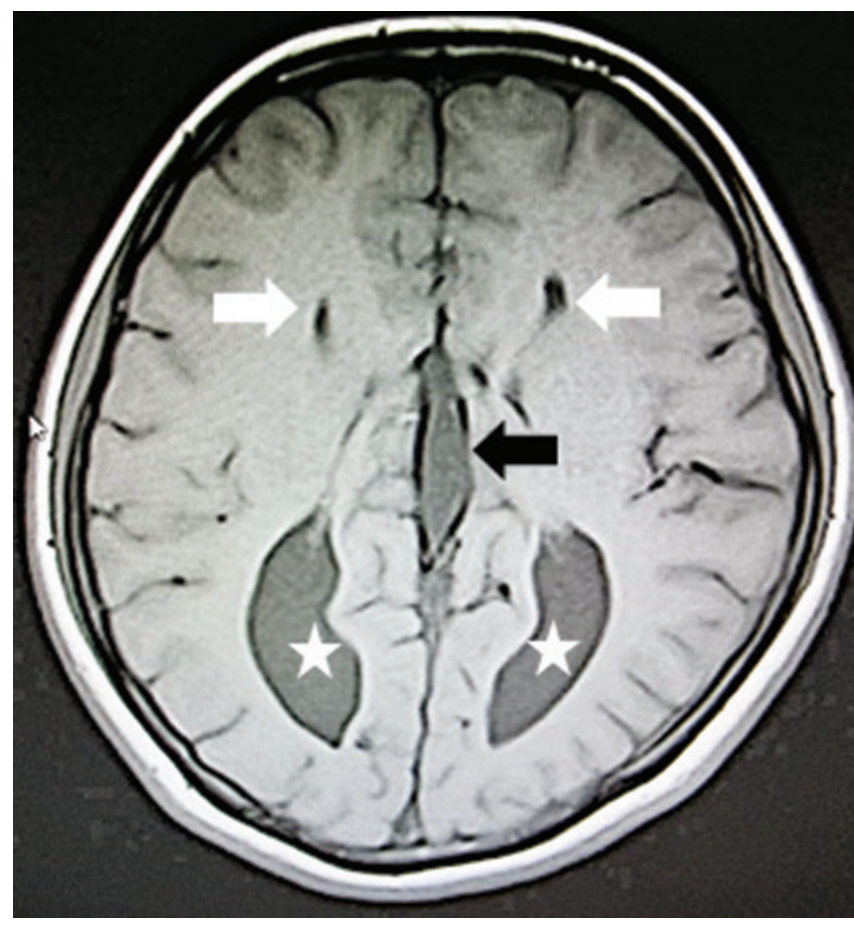

Figure 2. T1 cranial MRI sequence, axial view, showing lateral ventricles (white arrow) that run parallel to each other with dilatation of the trigones and occipital horns (white stars) and a high riding third ventricle (black arrow) indicative of a corpus callosum agenesis.

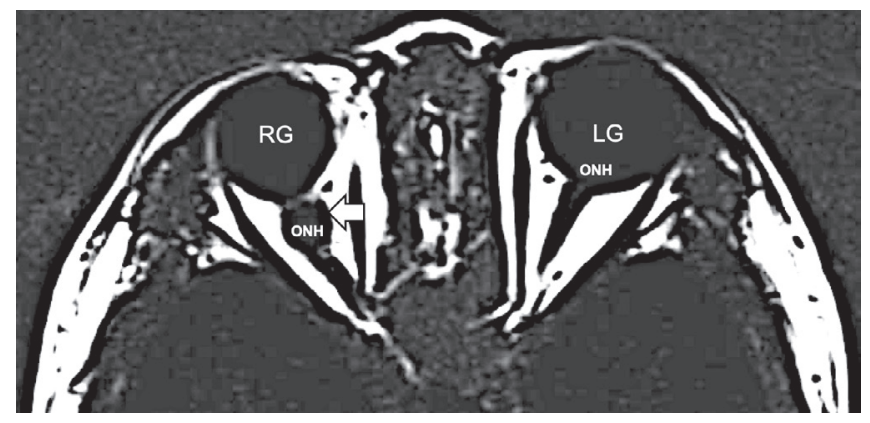

Figure 3. T2 orbital MRI sequence, axial view, showing a relatively smaller right globe (RG) with a posterior outpouching corresponding to the peripapillary staphyloma (white arrow) displacing the optic nerve head $(\mathrm{ONH})$ backward.

for a glaucomatous optic disc. However, unlike in glaucoma, intraocular pressure, visual field testing except for an enlarged blind spot and vision are within normal limits. ${ }^{13,14}$ The intraocular pressures of our patient were within normal limits but her vision is poor in the right eye. This can be explained by the coexistence of the peripapillary staphyloma which involved or "captured" the macula, similar to some reported cases of morning glory disc anomaly. ${ }^{15}$ Peripapillary staphyloma is a rare and one of the excavated congenital 
Table 1. Summary of clinical characteristics of all published Aicardi cases with normal cognitive functions

\begin{tabular}{|c|c|c|c|c|c|c|c|c|c|}
\hline Patient & $\begin{array}{l}\text { Age in } \\
\text { years }\end{array}$ & $\begin{array}{c}\text { Intelligence } \\
\text { Quotient }\end{array}$ & $\begin{array}{l}\text { Psychomotor } \\
\text { function }\end{array}$ & Language & $\begin{array}{l}\text { Seizure } \\
\text { episode }\end{array}$ & $\begin{array}{l}\text { Physical } \\
\text { Exami- } \\
\text { nation }\end{array}$ & EEG & Brain imaging & $\begin{array}{l}\text { Ophthalmological } \\
\text { findings }\end{array}$ \\
\hline Patient $1^{1}$ & 9 & 100 WISC-R & $\begin{array}{c}\text { At par } \\
\text { with age }\end{array}$ & $\begin{array}{c}\text { At par } \\
\text { with age }\end{array}$ & $\begin{array}{l}\text { Seizure } \\
\text { episodes at } \\
4 \text { years old } \\
\text { Seizure } \\
\text { relapse at } \\
7 \text { years old }\end{array}$ & Normal & $\begin{array}{l}\text { Paroxysmal } \\
\text { slow waves } \\
\text { and sporadic } \\
\text { spike-wave } \\
\text { complexes } \\
\text { in parieto- } \\
\text { occipital } \\
\text { regions }\end{array}$ & $\begin{array}{l}\text { Corpus callosum } \\
\text { (CC) hypoplasia } \\
\text { with polymicro- } \\
\text { gyria of the } \\
\text { parietooccipital } \\
\text { areas and } \\
\text { subependymal } \\
\text { heterotopias }\end{array}$ & $\begin{array}{l}\text { Chorioretinal lacunae } \\
\text { more than five times } \\
\text { the size of optic disk } \\
\text { diameter, both eyes }\end{array}$ \\
\hline Patient $2^{3}$ & 2 & $\begin{array}{l}110 \\
\text { Stanford- } \\
\text { Binet }\end{array}$ & $\begin{array}{c}\text { At par } \\
\text { with age }\end{array}$ & $\begin{array}{c}\text { At par } \\
\text { with age }\end{array}$ & None & Normal & Normal & $\begin{array}{l}\text { CC agenesis, } \\
\text { cysts in choroid } \\
\text { plexuses and in } \\
\text { the arachnoid } \\
\text { behind the third } \\
\text { ventricle }\end{array}$ & $\begin{array}{l}\text { Optic disc coloboma } \\
\text { and MGDA with } 2 \\
\text { chorioretinal lacunae less } \\
\text { than five times the size } \\
\text { of the optic disc, left eye }\end{array}$ \\
\hline $\begin{array}{l}\text { Patient } 3 \\
\text { (Present } \\
\text { case) }\end{array}$ & 14 & $\begin{array}{l}\text { 90-109 } \\
\text { Stanford- } \\
\text { Binet }\end{array}$ & $\begin{array}{c}\text { At par } \\
\text { with age }\end{array}$ & $\begin{array}{c}\text { At par } \\
\text { with age }\end{array}$ & $\begin{array}{c}\text { Few } \\
\text { infantile } \\
\text { spasms at } \\
1 \text { month } \\
\text { old }\end{array}$ & Normal & Normal & $\begin{array}{l}\mathrm{CC} \text { agenesis } \\
\text { with } \\
\text { colphocephaly }\end{array}$ & $\begin{array}{l}\text { Megalopapilla, peri- } \\
\text { papillary staphyloma and } \\
\text { chorioretinal lacunae less } \\
\text { than five times the size of } \\
\text { the optic disc, right eye }\end{array}$ \\
\hline
\end{tabular}

optic disc anomalies reported to be non-hereditary, often unilateral, and rarely associated with systemic diseases. ${ }^{16}$ Its pathophysiology is also unknown but theorized to be from insufficient development of the posterior sclera derived from the neural crest cells in-utero. ${ }^{17}$ It is associated with poor vision with only one pediatric reported case of achieving significant visual acuity improvement after occlusion therapy. ${ }^{16}$

She also has no intellectual disability. This was only found in two of the $800+$ reported cases ${ }^{1-10,18-32}$ of AS in the literature (Table 1). Aside from normal cognitive function, our patient also has no language or motor delay as opposed to patients originally described by Chevrie and Aicardi with no meaningful language and occasional ambulatory skills. ${ }^{10}$ Aside from the traditional triad and the new ophthalmological findings, she has none of the other associated physical findings of AS. She also does not suffer from hypo or hypertonia, hemiplegia, hemiparesis or quadriparesis. ${ }^{20}$ There was no burst suppression, quasiperiodicity, asynchrony, or hypsarrhythmia in her EEG. ${ }^{5,6,30}$ She also lived past the mean age at death of 8.3 years. This may be explained by her mild AS and the non-persistence of seizures after infancy which did not predispose her to aspiration pneumonia, the most common cause of death in AS. $5,6,8,12$

The smaller size of chorioretinal lesions, absence of heterotopia in brain imaging, unilaterality of eye involvement, and partial corpus callosum agenesis were proposed to improve cognitive prognosis. $1,3,5$ However, the patient described by Grosso et al with normal cognitive function had large chorioretinal lacunae in both eyes. ${ }^{1}$ Another had subependymal heterotopia and two patients have total agenesis of the corpus callosum..$^{1,3,4}$ Frequency and control of seizures were also tested if related to cognitive function prognosis. They were found to be unrelated and is supported by the finding that despite the achievement of seizure control, there is still slow psychomotor development noted in AS patients. ${ }^{3,5}$ Grosso et al. proposed that only genetic testing can explain the heterogeneity of AS including the mild presentation. ${ }^{1}$ However, while skewed X-inactivation was found in severe AS cases, Hoag et al. found no relationship between AS severity and the pattern of X-inactivation. ${ }^{9,20,28,29}$ Similarly, there are still no identified genes to explain AS despite wholeexome sequencing and examining skewed $\mathrm{X}$-inactivation, copy number variation, and around 8 candidate genes. ${ }^{30,31}$

AS is reported only in females (XX chromosomes) with an exemption of a male with XXY chromosomes. ${ }^{22}$ As such, it was initially proposed that AS is an X-linked dominant disease which is lethal in male while affected females are expected to have offspring with an equal chance of being unaffected male, unaffected female and affected female. However, to be proven, this requires that an affected male, who are presumed inviable hemizygotes leading to spontaneous abortions, needs to produce female offspring with AS. Offspring of a female with AS can also be analyzed but there are no reported AS patient with offspring yet. ${ }^{22}$ However, in a survey done on 69 AS patients, none of the parents and 106 siblings have AS. ${ }^{6}$ This, and our patient having no family history of AS, supports the hypothesis that AS is sporadic and simplex. ${ }^{6}$ However, despite the absence of report on motherto-child transmission, we advised the patient to undergo prenatal ultrasound when she gets pregnant to assess early the presence of corpus callosum in the fetus and postnatally, for the infant to undergo newborn eye examination and monitoring of seizure development. ${ }^{32}$

Central to monitoring AS patients is seizure control to prevent seizure-related aspirations and pneumonia and additional neurological complications. Genitourinary 
complications arising from anti-seizure medications and catheter use shall also be monitored together with growth and nutritional status which are often affected by the gastrointestinal manifestations of AS. Developmental level shall also be monitored to cater for the educational needs together with the possible progression of kyphosis or scoliosis if present. ${ }^{32}$ Lastly, occlusion therapy can be initiated on the affected eye to help improve vision, as has been done to our patient since it was her only concern at the moment.

This case highlights the significant role of ophthalmologists in diagnosing AS and other diseases with associated chorioretinal and optic nerve abnormalities since they can be the first to see the patient. It is important to differentiate especially early in life between the types of excavated congenital optic disc anomaly (MGDA and coloboma which have been previously associated with AS and recently in this case, peripapillary staphyloma) since each type can also be associated with a syndrome that can be lifethreatening when diagnosed late. MGDA can be associated with nasopharyngeal encephalocele and hypopituitarism as a syndrome, with constriction of the intracranial branches of both internal carotid arteries in Moyamoya syndrome or with cardiac anomalies in PHACE syndrome. ${ }^{33-35}$ Coloboma of the optic nerve can be associated with cardiac anomalies in CHARGE syndrome or with neurological abnormalities in Walker-Warburg syndrome. ${ }^{36-37}$ Familiarity with the updated disease description and proper examination are vital to differentiating one from the other. The use of ophthalmic diagnostic procedures such as fluorescein angiogram, optical computed tomography of the optic nerve head, and ocular ultrasound can make differentiation easier even for megalopapilla with large cup and glaucoma. In equivocal ophthalmologic assessments, especially since excavated congenital optic disc anomalies can co-exist, complete physical and neurological examinations will help identify a syndrome while cranial imaging is a good initial procedure to help in the diagnosis of $\mathrm{AS}^{38}$

\section{CONCLUSION}

Aicardi syndrome is a clinically heterogeneous, rare $\mathrm{X}$-link disorder traditionally characterized with a triad, severe psychomotor retardation, and poor prognosis. We presented a case of a Filipino patient with the traditional triad of AS but with peripapillary staphyloma, normal cognitive, language, and motor ability, no physical abnormalities and lived past the normal survival age. There is still no established factor that prognosticates cognitive function. As such, a good clinical eye and a high index of suspicion are needed to diagnose AS.

\section{Ethical Consideration}

The patient gave consent to this case report.

\section{Statement of Authorship}

Both authors participated in the data collection and analysis and approved the final version submitted.

\section{Author Disclosure}

Both authors declared no conflicts of interest.

\section{Funding Source}

No funding support.

\section{REFERENCES}

1. Grosso S, Lasorella G, Russo A, Galluzzi P, Morgese G, Balestri P. Aicardi syndrome with favorable outcome: Case report and review. Brain Dev. 2007;29(7):443-446. doi:10.1016/j.braindev.2006.11.011

2. Kroner B, Preiss L, Ardini M, Gaillard W. New Incidence, Prevalence, and Survival of Aicardi Syndrome From 408 Cases. J Child Neurol. 2008;23(5):531-535.

3. Viñas JP, Gonzalez M, Ribes A, Gonzalez S, Fernandez R. Callosal agenesis, chorioretinal lacunae, absence of infantile spasms, and normal development: Aicardi syndrome without epilepsy?. Dev Med Child Neurol. 2005;47(6):419-420. doi:10.1017/s0012162205000812.

4. Galdós M, Martínez R, Prats J. Síndrome de Aicardi: variabilidad fenotípica y factores pronósticos. Archivos de la Sociedad Española de Oftalmología. 2008;83(1).

5. Menezes A, Enzenauer R, Buncic J. Aicardi syndrome--the elusive mild case. British J Ophthalmol. 1994;78(6):494-6.

6. Glasmacher M, Sutton V, Hopkins B, Eble T, Lewis R, Park Parsons D, Van den Veyver I. Phenotype and Management of Aicardi Syndrome: New Findings from a Survey of 69 Children. J Child Neurol. 2007;22(2):176-184.

7. Kasasbeh A, Gurnett C, Smyth M. Palliative epilepsy surgery in Aicardi syndrome: a case series and review of literature. Child Nervous System. 2013;30(3):497-503.

8. Aguiar M, Cavalcanti M, Barbosa H, Vilela S, Mendonça J, Horta E. Síndrome de Aicardi e papiloma do plexo coróide: uma associação rara. Relato de caso. Arquivos de Neuro-Psiquiatria. 1996;54(2):313-317.

9. King A, Bowen D, Goulding P, Doran R. Aicardi syndrome. British J Ophthalmol. 1998;82(4):456a-456a. doi: 10.1136/bjo.82.4.456a

10. Chevrie J, Aicardi J. The Aicardi syndrome. In: Pedley TA, Meldrum BS, eds. Recent advances in epilepsy. Vol 3. Edinburgh: Churchill Livingstone, 1986: 189-210.

11. Lee H, Park S, Heo H. Megalopapilla in children: a spectral domain optical coherence tomography analysis. Acta Ophthalmol. 2014;93(4):e301-e305.

12. Brodsky MC. Congenital anomalies of the optic disc. In: Miller NR, Newman NJ (eds), Walsh \& Hoyt's Clinical Neuro-Ophthalmology, 5th ed. Philadelpia: Lippincott Williams \& Wilkins; 1998. p.755.

13. Randhawa S. Megalopapilla, Not Glaucoma. Arch Ophthalmol. 2007;125(8):1134.

14. Amador-Patarroyo M,Pérez-Rueda M,Tellez C. Congenital anomalies of the optic nerve. Saudi J Ophthalmol. 2015;29(1):32-38.

15. Lee B, Traboulsi E. Update on the Morning Glory Disc Anomaly. Ophthalmic Genet. 2008;29(2):47-52.

16. Kim S, Choi M, Yu Y, Huh J. Peripapillary Staphyloma. Arch Ophthalmol. 2005;123(10):1371.

17. Pollock S The morning glory disc anomaly: contractile movement, classification, and embryogenesis. Doc Ophthalmol. 1987;65:439- 60.

18. Rosser T, Acosta M, Packer R. Aicardi syndrome: spectrum of disease and long-term prognosis in 77 females. Ped Neurol. 2002;27(5):343-6.

19. Menezes A, MacGregor D, Buncic J. Aicardi syndrome: Natural history and possible predictors of severity. Ped Neurol. 1994;11(4):313-8.

20. Neidich J, Nussbaum R, Packer R, Emanuel B, Puck J. Heterogeneity of clinical severity and molecular lesions in Aircardi syndrome. J Ped. 1990;116(6):911-7.

21. Hopkins B, Sutton V, Lewis R, Van den Veyver I, Clark G. Neuroimaging aspects of Aicardi syndrome. Am J Med Genet Part A. 2008;146A(22):2871-8. 
22. Donnenfeld AE, Pacher RJ, Zackai EH, Chee CM, Sellinger B, Emanuel BS. (1989) Clinical, cytogenic and pedigree findings in 18 cases of Aicardi syndrome. Am J Med Genet. 32: 461-7.

23. Kroner B, Preiss L, Ardini M, Gaillard W. New Incidence, Prevalence, and Survival of Aicardi Syndrome From 408 Cases. J Child Neurol. 2008;23(5):531-5.

24. Banerjee T, Chattopadhyay A, Manglik A, Ghosh B. Aicardi syndrome: A report of five Indian cases. Neurol India. 2006;54(1):91.

25. Wang JH, Roan CD, Chang KP, Huang SS, Chi CS, Hwang BT. Aicardi syndrome--a case report. Zhonghua Yi Xue Za Zhi (Taipei). 1989;43(2):135-40. PMID: 2766069.

26. Altinbaşak S, Baytok V, Yalaz M, Onenli N. The Aicardi syndrome. A case report and review of the literature. Turk J Ped. 1993;35(4): 305-12. PMID: 8160283.

27. Yamamoto N, Watanabe K, Negoro T, Matsumoto A, Hara K, Miyazaki S, Takeuchi T. Aicardi syndrome. Report of 6 cases and a review of Japanese literature. Brain Dev. 1985;7(4):443-9. doi: 10.1016/s03877604(85)80145-5. PMID: 4061784.

28. Hopkins B, Sutton V, Lewis R, Van den Veyver I, Clark G. Neuroimaging aspects of Aicardi syndrome. Am J Med Genet Part A. $2008 ; 146 \mathrm{~A}(22): 2871-8$.

29. Hoag H, Taylor S, Duncan A, Khalifa M. Evidence that skewed X inactivation is not needed for the phenotypic expression of Aicardi syndrome. Human Genet. 1997;100(3-4):459-64.

30. Lee S, Kim K, Cho S, Lee S. An Atypical Case of Aicardi Syndrome with Favorable Outcome. Korean J Ophthalmol. 2004;18(1):79.

31. Wong B, Sutton V. Aicardi syndrome, an unsolved mystery: Review of diagnostic features, previous attempts, and future opportunities for genetic examination. Am J Med Genet C Semin Med Genet. 2018; 178(4):423-31.
32. Sutton VR, Van den Veyver IB. Aicardi Syndrome. In: Adam MP, Ardinger HH, Pagon RA, Wallace SE, Bean LJH, Mirzaa G, Amemiya A, eds. GeneReviews ${ }^{\circledR}$ [Internet]. 2006. [cited 2021 April]. Available from: https://www.ncbi.nlm.nih.gov/books/NBK1381/

33. Loddenkemper T, Friedman NR, Ruggieri PM, Marcotty A, Sears J, Traboulsi EI. Pituitary stalk duplication in association with moya disease and bilateral morning glory disc anomaly - broadening the clinical spectrum of midline defects. J Neurol. 2008; 255(6):885-90.

34. Scott R, Smith E. Moyamoya Disease and Moyamoya Syndrome. N Engl J Med. 2009;360(12):1226-37.

35. Rotter A, Samorano L, Rivitti-Machado M, Oliveira Z, Gontijo B. PHACE syndrome: clinical manifestations, diagnostic criteria, and management. An Bras Dermatol. 2018;93(3):405-11.

36. van Ravenswaaij-Arts C, Martin D. New insights and advances in CHARGE syndrome: Diagnosis, etiologies, treatments, and research discoveries. Am J Med Genet C Semin Med Genet. 2017;175(4): 397-406.

37. Nabhan M, ElKhateeb N, Braun D, Eun S, Saleem S, YungGee H et al. Cystic kidneys in fetal Walker-Warburg syndrome with POMT2 mutation: Intrafamilial phenotypic variability in four siblings and review of literature. Am J Med Genet A. 2017;173(10):2697-702.

38. Giuffré G, Distefano M. Peripapillary Staphyloma and Asymmetric Morning Glory Anomaly. Neuroophthalmol. 2006;30(2-3):53-7.

\section{The Acta Medica Philippina is now accepting limited advertising for its front and back cover (colored), as well as for available spaces in some of its pages, as appropriate. For inquiries and submission of proposals, please email us at actamedicaphilippina.upm@up.edu.ph}

